This is a pre-copy-editing, author-produced PDF of an article accepted for publication in the British Journal of Criminology following peer review. The definitive publisher-authenticated version 47 British Journal of Criminology (2007) 573-595 is available online at: http://bjc.oxfordjournals.org/content/47/4/573.full.

\title{
Killing Gay Men, 1976-2001
}

Peter Bartlett ${ }^{1}$

In recent years, there has been some concern in the academic literature over the use of the provocation defence in cases where gay ${ }^{2}$ men are killed by other men in a sexual context. (Banks 1997; Comstock 1992; Editors of the Harvard Law Review 1989, Lunny 2003; Mison 1992; New South Wales 1998; Oliver 1999; cf Dressler 1995). The typical case considered in this literature involves a sexual advance by the deceased, usually in the form of a grope or other physical approach, but occasionally merely as a salacious invitation. The extent to which sexual conduct actually results varies, but the subject of the advance eventually becomes violent, killing the person making the advance. The killer then pleads provocation, based on the sexual advance of the deceased, in hopes of reducing a murder to manslaughter.

The literature is written from a legal perspective, and is understandably critical of the use of the provocation in this fashion. This raises interesting questions regarding the law, but tells us little about gay homicide. This paper has the reverse objective. By examining a range of cases, it raises questions about the nature of gay sexual homicide.

The primary claim of this paper is that sufficient consistencies can be shown in the cases studied here and in the related literature that gay sexual homicide constitutes a coherent object of study. That is in itself a significant finding. Gay men are dying, and the circumstances in which that is taking place warrants analysis in its own right. The cases are of broader intellectual interest, however. The existing literature relating to sexual crime pre-supposes a male assailant and a female victim. This is true both of the sociology of masculinity and also the psychological literature. The cases in this study present sexual crime in a context where women are absent, and as such raise questions about the scope, assumptions and findings of that literature.

\footnotetext{
${ }^{1}$ School of Law, University of Nottingham. I would acknowledge with thanks the assistance of the Home Office for allowing me to make use of the Homicide Index to identify relevant cases. I would further acknowledge the assistance of the Crown Prosecution Service in allowing me access to their files and providing a congenial working environment during the collection of the empirical data in this paper. The good-natured co-operation of the CPS made a variety of practical problems disappear, and I am very grateful for the assistance of their staff. During the rather long gestation of this project, I was fortunate to receive academic residency at the Wellcome Trust Centre for the History of Medicine at University College London and the School of Law at Birkbeck College, London. I am grateful to both for the collegiality offered during my time there. Drafts of the paper have been read by a number of people, including Les Moran, Jill Peay, Colin Richardson and Stephen Tomsen. All provided helpful and inciteful comments. Similarly, the anonymous reviewers for the British Journal of Criminology provided comments that really were very helpful: many thanks for what is so often a thankless task. Last, and certainly not least, I am grateful to the Small Grants programme of the British Academy for funding much of the data collection costs of this research.

2 'Gay' in this paper is used to include bisexual men, and men who have sex with men but do not selfidentify as gay or bisexual.
} 
The Parameters of the Empirical Data

While the homosexual advance situation served as the original paradigm for cases of interest, it became clear early in the research that it would be arbitrary not to include other cases involving deaths occurring during gay sexual encounters. At the same time, the decision was made to exclude homicides of men by their ongoing gay partners, as it was assumed rightly or wrongly that such cases would be essentially similar to heterosexual domestic killings, or that they would in any event be sufficiently qualitatively different from the original paradigm as to warrant a different study. As a result, the cases at the core of this study involve deaths related to relatively casual sexual activity.

The detailed empirical analysis is based on a reading of the files of the Crown Prosecution Service relating to such cases. Several mechanisms were used to identify cases for an initial data set. The Home Office keeps an index of all homicides, the Homicide Index. It is computerised from 1976, and this date was therefore selected as the start date for the data for this paper. The database includes fields relating to the relationship between the deceased and their killer. 'Homosexual: Casual' is one such relationship, and cases coded as such were included in this study. In addition, cases were included in which both accused and deceased were male, and the circumstances of the case were defined as sexual. Other cases were drawn from a reading of reported case law, and from cases encountered somewhat idiosyncratically in both the general and gay press. Finally, the staff at the Records Office of the Crown Prosecution Service themselves occasionally became aware of cases of relevance, and they kindly passed those references on.

From this initial data set, various exclusions were made. Killings related to paedophilia were considered to be sufficiently different from the core interest of the paper that cases were excluded where the victim was under the age of 16 years at the time of his death. Other cases were excluded that manifestly did not fit the criteria above, as for example a case where accused and deceased were both male, but the sexual activity related to the rape of a woman occurring in the same train of events as the homicide. As detailed research would be undertaken at the Crown Prosecution Service, cases outside England and Wales were excluded from the data set. Inevitably, there have been borderline cases: when, for example, does a casual relationship turn into a domestic arrangement? In general, I have erred on the side of inclusion. A final set of exclusions was enforced by practicality. The Crown Prosecution Service is meant to retain all homicide records, but some have gone astray. Such cases were perforce excluded from close empirical study.

In the end, the study considers the deaths of seventy-seven people, resulting in the conviction of seventy-eight people. This cannot be considered a complete sample of gay sex-related murders in this period. In addition to the contingencies identified above, cases enter the sample only if a perpetrator was identified: otherwise the file would not have been sent to the Crown Prosecution service, and the evidential materials on which this study is based would not exist. Further, while the coding at the base of the Homicide Index has general academic respect, it cannot be considered perfect. The use of news reports to buttress the data set can also not be considered satisfactory for formal statistical purposes, as it may be subject to statistical biases of 
its own. The number of cases is significantly larger than contained in much of the other published literature on gay murder, ${ }^{3}$ but this too does not preclude potential sampling bias.

The data set in published literature most closely resembling this one is that in Stephen Tomsen's study in New South Wales (Tomsen 2002). Tomsen considers deaths of 74 men, of which only 54 were solved and 38 subjected to close scrutiny. His interest is in murders flowing expressly or implicitly from an anti-gay animus, so a significant number of these cases occur outside an express sexual context.

Nonetheless, his study is sufficiently close to this one to be useful for comparative purposes, and will be cited below.

A more extensive statistical data base has been compiled by Mr Colin Richardson, the former editor of Gay Times, based primarily on local newspaper reports. Mr Richardson very kindly made this available for comparative purposes. That database adopts somewhat different parameters from mine, ${ }^{4}$ and has both the advantages and disadvantages of reliance on newspaper reports. ${ }^{5}$ It contains 256 cases between 1985 and mid-2003, of which 188 had at that time been solved. While our databases overlap, they are not identical: just under half of the deceased in my database for 1985 to 2000 do not appear in Mr Richardson's data. The statistical prevalences in my work are nonetheless broadly consistent with Mr Richardson's database, providing some support for the representativeness of the current sample. At the very least, the quantitative indicators below can serve as a useful shorthand to describe the cases considered.

\section{$\underline{\text { The Records }}$}

The empirical data upon which this study is based is found in the relevant files of the Crown Prosecution Service. These files generally contain reports by police officers and junior counsel summarising the case, a correspondence file, full copies of statements by potential witness and the accused, psychiatric and similar expert reports, a note of the verdict, and, generally, some account of the trial. Sometimes, particularly in the earlier years, the account will be a brief report, usually by junior counsel for the Crown. In later cases, there will often be the trial notebooks of counsel. There are also pictures of the scene of the homicide, and of the body of the deceased.

While the records therefore constitute a very rich source of empirical information, they are not unproblematic for purposes of this paper. They are compiled with an objective of deciding whether a case ought to go to trial, not with the objective of understanding gay sexual homicide. Issues which might be key to this paper are not necessarily key to a police investigation. Motive, for example, will be touched on by police, but it is not formally required for a finding of guilt, and may be of less concern in cases where compelling forensic evidence exists that the accused performed the homicide. Demographic factors about the accused and deceased,

\footnotetext{
${ }^{3}$ See eg Mouzos and Thompson 2000, which relies on 29 cases; New South Wales 1998, which uses 13 cases; Gemert 1994, which uses 18 cases.

${ }^{4}$ It contains cases of sexuality-related homicide outside an expressly sexual context, for example, and includes cases from across the United Kingdom, not merely England and Wales.

${ }^{5}$ Regarding reliance on newspaper reports, see Janoff 2005: chapter 1.
} 
similarly, are not relevant to guilt. While the files do generally contain a witness statement providing a basic background account, and psychiatric reports on the accused are similarly helpful, this is not the object of the case file.

The information contained in the files must similarly not be viewed uncritically. Statements by accused persons are made to the police, the people in charge of mounting the prosecution against the accused. They are not disinterested reflections on an individual's actions. At one extreme, sometimes an accused will exercise his right not to make a statement. As the other person who had been present during the crime is ex hypothesi dead, this leaves no direct account of the homicide. There may in such cases be compelling forensic evidence that the accused killed the deceased, but there is no account of why. Even if the accused does make a statement, it would be naïve to pretend that the statement is not affected by the circumstances in which it is made.

The situation is made more complex by the fact that the police interviewing techniques result in multiple accounts by accused persons. ${ }^{6}$ The interview normally has three parts. The first allows the accused considerable scope to tell the story in his own words. The second is much more directive, with the police pressing the accused on details. The final part can be quite aggressive, with the police officers challenging the accused on aspects of the story that do not appear consistent. If the accused then changes his story, the process repeats itself until either the accused has nothing more to say, or the officers are satisfied with the account provided. The file may therefore contain a variety of inconsistent accounts by the accused. This process may continue well after the police interviews are concluded. For example, the psychiatric reports may contain an account by the accused very much at odds with the version provided in the police interview.

These raise obvious difficulties in interpretation. Even with demographic information, there are inconsistencies. This explains why the quantitative indicators below are sometimes reported in the form of a range, rather than a firm number.

\section{The Cases and the Protagonists}

Analysis of quantitative indicators shows a considerable consistency across the cases. The consistency between this and other similar studies in this regard suggests that gay sexual killings constitute a coherent class for study.

\section{Participants and Locations}

Seventy-eight people were convicted of the 77 deaths in this study. More people than the deceased and a sole assailant were present in only six or perhaps seven of these cases. ${ }^{7}$ Far and away the typical case in my sample is therefore the individual assailant killing a lone deceased person. Similarly, the considerable majority of perpetrators were associated with only one killing. Only three of the perpetrators in the sample were associated with deaths of more than one person in the

\footnotetext{
${ }^{6}$ Regarding the active role of the police in construction of cases, see Sanders 1997: ch.29; McConville et al 1991; Sanders, 1987.

${ }^{7}$ These include cases where other persons were present but not convicted of a crime related to the death.
}

Pink_paper4_public_harvard.dft.doc - 4 - 
sample. Two additional killers in the sample were convicted in addition to at least one non-gay homicide. Of the 77 deceased, ten were killed by persons killing more than one person. The usual picture that results is therefore of a killer acting alone, who has not killed someone previously. Sixty of the 77 deaths $(78 \%)$ match that description.

This is an image somewhat different from Tomsen's sample, where 23 of the 55 solved homicides involved more than one perpetrator. ${ }^{8}$ This may be the result of Tomsen's different parameters, which include attacks outside a sexual context. Traditional hate crimes tend more frequently to be perpetrated by groups (Hamner 1992; Comstock 1991; Craig, 2002). This is consistent with Tomsen's own analysis, which distinguishes two general scenarios accounting for the bulk of his cases: attacks in public spaces by groups on people perceived to be homosexual; and one-onone attacks in private spaces, which give rise to allegations of sexual advances (Tomsen 2002). Applying that distinction, the preponderance of cases in the current study fall more closely into the latter category. Consistent with this, 78 per cent of deaths in the current sample occurred in the home of the victim, of the assailant, or of both: see table I. Only three or perhaps four deaths in the current study appear to have occurred in outdoor gay cruising areas and twelve (16\%) in other public areas. These figures for deaths in public spaces are lower than Tomsen's for the reasons indicated; the figure for deaths in cruising areas is also slightly lower than Richardson's data set, ${ }^{9}$ albeit on a very small base. Richardson's figure for deaths occurring in public areas is markedly similar to my own, at 17 per cent of all murders and 13 per cent of solved murders.

\section{Table I: Locations}

\begin{tabular}{|l|l|l|} 
Location & Number & $\begin{array}{l}\text { Percent of total } \\
\text { deaths }\end{array}$ \\
\hline Deceased's home/hotel/private office/etc & 49 & 64 \\
\hline Assailant's home & 6 & 8 \\
\hline Home of both assailant and deceased & 5 & 6 \\
\hline $\begin{array}{l}\text { Public areas (incl building sites) (not cruising } \\
\text { areas) }\end{array}$ & 12 & 16 \\
\hline Cruising areas & 3 & 4 \\
\hline Deceased's car & 2 & 3 \\
\hline Total & 77 & 99
\end{tabular}

Relations between assailants and deceased were roughly equally divided between strangers (45\%) and non-strangers (49\%). ${ }^{10}$ This is a somewhat lower proportion of strangers than in Richardson's set of solved murders $(60 \%)$. Tomsen divides his sample slightly differently: roughly one third of his victims were killed by people they did not know, and half of the victims killed in private dwellings 'barely' knew their assailants. Overall, 45 of his 74 victims did not know or barely knew their

\footnotetext{
${ }^{8}$ Tomsen does not provide statistics for the number of killers in his study who have killed before.

${ }^{9}$ In Richardson's database, 9 per cent of solved murders and 12 percent of all murders occurred in cruising areas or cottages.

10 'Non-strangers' here includes acquaintances, friends, workmates, and so forth. Relationship between the remaining assailants and victims was unknown.
}

Pink_paper4_public_harvard.dft.doc - 5 - 
assailants at the time of the deaths (Tomsen 2002: 25). His conclusion is that stranger violence is much more significant here than in attacks on women, or general attacks on men. The current study is consistent with that view. Between 1985 and 1994, roughly 23 per cent of victims overall, and 39 per cent of men killed in England and Wales were killed by strangers (Soothill et al 1999: table E.5). At the same time, circumspection is called for. Certainly, there are cases in the sample of men killed by previously unknown men met in bars and brought home ostensibly for sex; but more men were killed by people with whom they were at least acquainted twenty-four hours before the killing.

\section{Methods of Homicide}

Table II indicates the methods of homicide of the 77 men in this study, with statistics for men killed by strangers and acquaintances generally in England and Wales as a comparator. Insofar as the statistics are comparable, ${ }^{11}$ the current sample shows fewer than expected deaths by sharp instruments, shooting and hitting or kicking. Deaths by hitting with a blunt instrument and strangling or asphyxiation are noticeably more prevalent. Tomsen's data diverge from this, with a higher prevalence of punching and kicking (45\%), but he notes that these are mainly related to deaths caused by groups of people. His incidence of strangulation, asphyxiation and drowning is also notably lower, at 12 per cent.

\section{Table II: Method of Homicide}

\begin{tabular}{|l|l|l|l|} 
& Number & $\%$ & $\begin{array}{l}\text { England/Wales, 1985-94, } \\
\text { Men killed by strangers or } \\
\text { acquaintances (\%) }\end{array}$ \\
\hline Sharp instrument & 23 & 30 & 41 \\
\hline Blunt instrument & 24 & 31 & 12 \\
\hline Hitting/Kicking & 6 & 8 & 17 \\
\hline Strangling/asphyxiation/drowning & 23 & 30 & 7 \\
\hline Fire & - & - & 3 \\
\hline Shooting & - & - & 10 \\
\hline Drug OD & 1 & 1 & \multirow{2}{*}{\}} \\
\cline { 1 - 3 } Other & - & - & 11
\end{tabular}

The methods of homicide are interesting in part because of what they suggest about prior intent to kill. As was the case in Tomsen's sample, it is relatively rare that an intention to kill was manifest prior to the attack. ${ }^{13}$ Two of the five killers of multiple victims in the current study had clear and previously formed intentions to kill

\footnotetext{
${ }^{11}$ There is a complication regarding comparisons here, as the statistics contained in Soothill et al 1999 include distinguish men killed by 'partner/lover/girlfriend'. Insofar as the homicides in the current study would have been included in that category in those statistics, the differences identified in the discussion are even more marked: 66 per cent of those men were killed by a sharp instrument and 7 per cent asphyxiated. Apart from 'other' at 10 per cent, no other category reached more than 5 per cent of these homicides. It should however be noted that these statistics are based on only 41 men killed in this way, between 1985 and 1994.

${ }^{12}$ These statistics are drawn from Soothill et al 1999: 112.

${ }^{13}$ This was the case for only 16 of Tomsen's 92 perpetrators or co-perpetrators: Tomsen 2002: 25.
} 
people well before the deaths occurred, but they are very much the exceptions. While a number of cases are consistent with the perpetrator anticipating a robbery, in which some violence would be expected, in the more usual case, there is no evidence to suggest that the accused anticipated their encounter with the deceased would escalate into violence.

Consistent with this, in only 20 cases was the deceased killed by a weapon brought to the scene by the assailant, apart from the assailant's clothing. Perhaps unsurprisingly, individuals killing more than one person account for many of these: two assailants were responsible for 7 of these cases. An additional 8 people were killed by an article of the assailant's clothing, typically a belt or dressing gown cord. In 8 cases, no weapon or implement was used, apart from the hands and feet of the assailant. In 30 cases, however, the assailant used a weapon or implement brought to the scene by the deceased. Knives in the deceased's home are the most frequent item in this category, accounting for 14 deaths, but assailants also used what came to hand, such as household ornaments or bits of furniture. In 7 cases, the instrument of death was brought neither by the assailant nor the deceased (such as a stone or other heavy object found at the scene in deaths occurring outdoors) and in four cases the providence of the weapon was uncertain.

For all deaths in the current sample, at least one person was convicted of homicide, be it murder or manslaughter. The defendant complained to the police, third parties or the court of an unwelcome sexual advance by the deceased in roughly 39 to 42 cases; the files are occasionally unclear. Provocation was pleaded 31 times, of which 13 pleas were successful at trial to reduce the conviction to manslaughter. The Court of Appeal reduced another three murder convictions to manslaughter on this basis. Of the successful provocation pleas, four cannot be considered as related to homosexual advances. Diminished responsibility was pleaded 20 times, reducing the conviction at trial to manslaughter in 12 of those cases, with another conviction reduced to manslaughter by the Court of Appeal. Self-defence was pleaded seven times, never successfully. An additional 7 accused were found guilty of manslaughter based on no intent to kill or cause serious bodily harm.

A variety of variables allow a broad picture to be created of both perpetrators and victims of the violence.

\section{Drugs and Alcohol}

Alcohol is frequently a factor in the scenarios surrounding the offences. The 77 deceased and 78 assailants yield a total of 85 perpetrator/victim combinations. The CPS files are not necessarily clear on alcohol consumption. Sometimes, for example, an accused will not be arrested until well after the killing, and alcohol consumption will be a matter of recollection by the accused, if indeed the accused chooses to make a statement. At other times, a body may not be discovered for some time, making analysis of the alcohol consumed at the time of the homicide problematic. Nonetheless, it would appear that for the 85 combinations noted above, between 51 and $71(60-84 \%)$ of the perpetrators had been drinking prior to the homicide. Of the 77 deceased persons, between 44 and $56(57-73 \%)$ had been drinking prior to the homicide. 
Drug abuse appears to be considerably less significant. Certainly, the files indicate that many of the perpetrators had a history of drug use. Most frequently, this involved marijuana; occasionally there was a history of glue sniffing. It is much more difficult however to tie the drug use into the events relating to the deaths. Of the 85 perpetrator/victim combinations, there were between 12 and 14 instances where the assailants were under the influence of drugs at the time of the attacks. Of these, three were on amphetamines, one on heroin, one on valium, one ingested hash, and four had smoked marijuana. The specific drug was not clear for the remaining four. In addition, three cases had apparent direct connections with drugs: one case involved a robbery, apparently to obtain money for drugs, and two assailants were experiencing withdrawal from drugs (one valium, the other heroin) at the time of the attacks.

Age

Overall statistics regarding ages of the protagonists are contained in table III. Consistent with Tomsen's sample,(Tomsen 2002: 18) the perpetrators in this study tended to be young, with 15 (19\%) of the killers under the age of 20, and an additional $47(60 \%)$ under 30 . The median age was 23 . Victims by comparison were older, with $48(62 \%)$ over the age of 40 , and an additional $14(18 \%)$ over the age of 30. Median age for victims was 43. This is broadly consistent with Richardson's database, where the average age of victims was just over 40, and with Tomsen's sample, which also showed ages of victims tending towards 30s and 40s (Tomsen 2002: 17). This is in contrast to the overall pattern of homicides in England and Wales. Of 2123 men aged over 15 killed by acquaintances or strangers between 1985 and 1994, only 67 per cent were over 30, compared to 80 per cent in the current sample. These homicides tend to involve younger men killing older men. This is consistent with, but more pronounced than appears to be the case for comparable heterosexual crime. In Grubin's study of heterosexual sexual murder, for example, the mean age for the male assailants was 30 , and for the female victims 38 (Grubin 1994).

This age disparity in the sample of gay homicides does diminish somewhat as the age of the assailant increases, but it never disappears. Even regarding the 5 killers aged 41 to 60 , three of the five people they killed were older than the perpetrators, by 15 to 21 years.

Table III: Age of Victims and Perpetrators

\begin{tabular}{|l|l|l|l|l|l|l|l|l|}
\hline & $\begin{array}{l}\text { <age } \\
20(\%)\end{array}$ & $20-29$ & $30-39$ & $40-49$ & $50-59$ & $60+$ & Total & $\begin{array}{l}\text { Median } \\
\text { Ages }\end{array}$ \\
\hline Victims & $3(4)$ & $12(16)$ & $14(18)$ & $24(31)$ & $14(18)$ & $10(13)$ & $\begin{array}{l}77 \\
(100)\end{array}$ & $\begin{array}{l}43 \\
78 \\
(99)\end{array}$ \\
Killers & $15(19)$ & $47(60)$ & $11(14)$ & $3(4)$ & $1(1)$ & $1(1)$ & 23 \\
\hline
\end{tabular}

Socio-economic Class

It would appear that, as in Tomsen's study, the 78 perpetrators in the current study were drawn disproportionately from poor and marginalised social groups. As shown in table IV, 61 (78\%) were on benefits or unemployed at the time of the 
killing; only two were from a managerial or professional background. Both of those were students, who were classified according to the employment of their custodial parent(s); one killed as part of a group in which the other members were on benefits or unemployed. ${ }^{14}$ Roughly half had attended a special school or borstal, or had been placed in care in their childhood. The CPS files show evidence of violent behaviour for between 48 and 53 of them (62-68\%) prior to the murder. Seventy-four (95\%) had a history of offending prior to the homicide; $37(47 \%)$ had a prior conviction for a violent offence.

The victims were somewhat less socially marginalised, although still, 45 per cent were on benefits, unemployed, or pensioners. The next most numerous category was however management or professionals at $25 \%$, however.

\section{Table IV: Employment Status}

[Note: students $(n=6)$ are classified on the basis of the higher of their custodial parents' status.]

\begin{tabular}{|l|l|l|l|l|l|l|} 
& $\begin{array}{l}\text { Benefits, } \\
\text { Unempl, } \\
\text { Pension }\end{array}$ & $\begin{array}{l}\text { Manual, } \\
\text { Blue } \\
\text { Collar }\end{array}$ & $\begin{array}{l}\text { Clerical, } \\
\text { small bus, } \\
\text { hospitality } \\
\text { etc }\end{array}$ & $\begin{array}{l}\text { Managem } \\
\text { ent or } \\
\text { profession } \\
\text { als }\end{array}$ & Unknown & Totals \\
\hline Killers & $61(78 \%)$ & $11(14)$ & $4(5)$ & $2(3)$ & - & $78(100 \%)$ \\
\hline Victims & $35(45 \%)$ & $7(9)$ & $15(19)$ & $19(25)$ & $1(1)$ & $77(99 \%)$
\end{tabular}

Childhood sexual abuse is interestingly relatively rarely mentioned in the documents. Psychiatric reports are contained in the files for 61 of the 78 assailants. These reports routinely include sections on psychosexual development and life history. Reports for only 13 of these 61 accused refer to sexual abuse in childhood, including two cases where other reports disputed the existence of the abuse, and two others where the severity of the abuse is unclear.

\section{Sexual Orientation}

Sexual orientation is a difficult category, both because it is ambiguous in its application (how 'gay' is gay?) and because even more than for other categories, information contained in the CPS file is not necessarily complete, or able to be adopted uncritically. There may be cogent reasons, for example, why an accused person might wish his gay sexual orientation not to form part of the CPS case, and would therefore conceal it. Particularly in more recent years, perhaps as a result of concerns that the sexuality of the deceased not become the focus of sensationalist defences in the subsequent trials, the CPS files did not always mention the sexual orientation of the deceased. ${ }^{15}$ That said, in a study of sexual murder of men by other

\footnotetext{
${ }^{14}$ The disproportion is higher here than in Tomsen's study, where of 54 perpetrators whose employment status was known, 22 (41\%) were unemployed (Tomsen 2002: 21). This is in part because he includes sex workers ( 5 cases, $9 \%$ ) as a separate category, where in the current study they were included as receiving benefits when there was evidence that they did so, but this does not account for the entire discrepancy.

${ }^{15}$ The quarter century of cases considered in this study of course span significant changes in the practices of the police and the prosecution services. Non-discrimination in policing and prosecution
} 
men, some engagement with the sexual orientation of the protagonists cannot be avoided. For the deceased, it is relatively easy. As one might perhaps expect, the considerable majority of the deceased were known to enjoy sexual relations with men other than their assailants: in only nine cases was there any serious reason to doubt that.

For perpetrators it is not so easy, as some appear to fall near to boundaries of sexual orientation. Issues also arise as to how to categorise persons who engage in sex with men for money: is this or is it not evidence of a homosexual orientation? If 'gay' is understood to mean having had sex with another man previously, without payment, somewhere between 35 and 49 of the killers in this study (45 to 63\%) were gay. This is relevant not merely for the one-on-one murders, but also for groups. Of the six or seven deaths where perpetrators acted as a group, three of the groups contained gay people.

This raises a set of difficult questions for gay analysts and commentators on these murders. We have long viewed violence against us by heterosexuals as part of our shared cultural history. The current study suggests however that we must understand gay people not merely as the victims of violence, but also a significant amount of the time as perpetrators of that violence, at least in the context of gay sexual homicide. A simple division between gay victim and non-gay perpetrator is not sustainable.

As noted above, sexual orientation is a difficult category. It is not merely that it is difficult to obtain reliable information as to the sexual behaviours of the protagonists in this study; it is also that different homosexual acts may be read differently, by different people. It is at least arguable, for example, that to be the 'passive' partner in anal penetration by another man is viewed by some men as particularly threatening to their understanding of their masculinity, in a way that other homosexual acts are not. ${ }^{16}$ Sometimes these reactions occur in unexpected ways, as illustrated in the following comment from one of the killers:

I've give, I've give somebody a blow job with a condom on and that's it that's the most I've ever done. I've never even, I mean that's even worse than buggery, kissing people that's even worse than buggery you know what I mean it's just disgusting.

Individuals may also relate differently emotionally to their sexual behaviour: some people are comfortable in their sexual orientation, some are not. The specifics of the construction of homosexuality and masculinity may therefore be pivotal to an understanding of violent responses in a sexual context. Sadly, the information in the CPS files is not sufficient to gain any systematic insight into this sort of nuanced selfperception of the gay perpetrators in the study. Psychiatric reports are contained for 63 of the 78 perpetrators. While these reports sometimes report on the general homosexual experiences of their subjects, they do not generally recount in significant

has entered the agenda particularly since the mid-1990s, and was adopted as formal CPS policy in 2002. The process of integrating policies against homophobia and for non-discriminatory attitudes onto previous structures of law, policing and prosecution are outside the scope of this paper.

${ }^{16}$ See, eg., Lunny 2003: 314. For a different reading of working class gay masculine identity, in which the symbolic meaning of passive sodomy appears to be less significant, see Connell 2000: 114-118.

Pink_paper4_public_harvard.dft.doc $\quad$ - 10 - 
detail the individual's understanding of their sexual self, or their comfort with their sexual orientation. This is consistent with the role of the reports as identifying diagnoses relevant to defences of diminished responsibility or insanity. Trial reports are not intended to provide a psychological account of how the murder happened, in a manner pleasing to social science researchers.

\section{Getting a Sense of the Cases}

From the above profiles, it is possible to get an overall sense of the cases. For almost all, there is no indication of a prior intent to kill; the exceptions are some, but not all, of the cases where one individual kills more than one person. Victims are generally older than their killers, often by a matter of decades. Usually, only the victim and his assailant are present at the time of the death. The killers tend to come from poor or marginalised social groups. Most perpetrators, and many of their victims, will have been drinking. Normally, the deaths occur in private space possessed by the deceased, usually his home. The deceased was generally gay, although no assumptions should be drawn about the sexual orientation of the perpetrators. Exceptional violence in the deaths is common, particularly in the oneon-one homicides. A few examples may give an additional flavour to the statistics.

The following case presents a relatively simple example. It concerns the death of an elderly man at the hands of a man in his early 20 s, a former resident of a hotel in which the deceased worked. The statement of the accused to the police contained the following account:

I asked him for my mail. He said there was none. He then asked how I was getting on at the Hotel [to which the accused had moved]. I said, "Okay everything is going fine." He then came towards me and put his arms around my shoulders and looked like he was going to kiss me on the face. He said he fancied me and wanted to go to bed with me. I told him to piss off. He carried on coming towards me so I hit with my hands and my feet. I was revolted by what he was doing. I lost my sense of reality and kept going. He tried to hit me but I was faster than him. At first he was standing up then he fell back on the bed. Whilst he was on the bed I punched him in the face and throat and kicked him in the face and chest. I then tried to rip his throat out with my hands and as I did so he fell so he was half on and half off the bed. I kept on hitting him. Then I saw all the blood on my hands, his face, and throat. I then ran.

The exceptional aggression is typical of these cases. In this case, there was no indication that the assailant was gay. There was an allegation that he was sexually abused as a child. Both deceased and the assailant had been drinking, the equivalent of one and a half pints in the case of the former, and six pints in the case of the latter. The loss of sense of reality is fairly common in these cases. Often, the assailants provide no coherent explanation of the death. While the advance might reasonably be understood as offensive to a heterosexual man, it does not account for the violence of the response. 
Analysis of the cases shows that deceased and the assailant meet in a variety of ways, although meeting in a pub and then proceeding to the deceased's home together is a particularly common scenario. As will be discussed further below, the expectation of a sexual encounter in these circumstances is of different degrees of explicitness, and would seem to be read in a variety of ways by different participants. Nonetheless, two specific fact scenarios warrant initial consideration, both because they are part of the literature and police accounts of gay homicide and because they are in the end unsatisfying as accounts.

\section{Robbery as a Context for Homicide}

A number of the cases are perceived by the police in the context of robberies. The usual script of these robberies as understood by the police is that sexuality is held out by the assailant as a way of making a connection with a potential victim, and as a way of gaining entry to the victim's house. The expectation would seem to be that a gay victim is less likely than a straight one to report the robbery, because of a desire to avoid an explanation as to why the robber was invited into the house: the police have not traditionally been viewed as sympathetic to gay men who have one night stands.

There are certainly cases that conform to this model. Certainly, there is evidence that some of the assailants are unscrupulous, and clearly, some of the murders occur in the context of robberies. Why the matter develops into a homicide is less clear. Consider the following case, where two men go home with the victim on the representation that one of them will have sex with the victim. According to one (A1, below), ${ }^{17}$ the other assailant (A2) and the victim do go into the victim's bedroom together and begin to have sex:

Q What happens next?

A1 Everything goes wrong.

Q Why does it go wrong?

A1 Goes wrong.

Q Why does it go wrong A1?

A1 (speaks very faintly) just goes wrong.

Elsewhere, the assailant mentions the sense that what was happening could not be real. His accusation is that the other accused did the homicide, a view with which the other accused eventually agrees, although each accused suggests that the other was the one engaged in sexual behaviour with the deceased. According to the actual killer, as reported to his psychiatrist, it was the sight of this sexual activity with the other assailant that triggered the fatal assault. This is related by the psychiatrist to a series of homosexual assaults the assailant states he suffered in his youth. At this point, the robbery theme converges with themes running through other cases, raising the question of how different the robbery cases are.

The case documents, written by the police and the prosecution counsel, seem occasionally to imply that the contextualisation of a case as robbery or, less

\footnotetext{
${ }^{17}$ To preserve anonymity, all assailants in quoted material will be referred to as A, and all deceased persons as D. When it is necessary to distinguish between different assailants in a single quote or series of quotes relating to the same case, they will be identified as A1, A2 and so forth.
}

Pink_paper4_public_harvard.dft.doc - 12 - 
frequently, blackmail moves it out of the realm of sexual homicide. This may make strategic sense in the preparation of a case: robbery is presented as the primary theme, and more complex issues relating to sexuality, with the smearing of the character of the deceased in court that this may entail, is minimised or its relevance marginalised. In 26 cases in the sample, the robbery scenario forms part of the police report or prosecution brief; blackmail figures in an additional 6 cases. In 18 of the 'robbery' cases and all the 'blackmail' cases, this characterisation is either challenged by the defence or is not wholly factually convincing. Too frequently, nothing of value was stolen, even if it was there for the taking. Alternatively, the theft concerns items necessary to effect an escape.

Perhaps more importantly for present purposes, it is difficult to see that the robbery or blackmail element removes the case from the umbra of sexual homicide. With one possible exception, ${ }^{18}$ these are not standard robberies that have gone wrong: they were deaths occurring in a sexual context. In a particularly clear example, two assailants formed a plan to rob an individual they had picked up in a gay bar. The plan was apparently not formulated until after they arrived at the individual's house. They sought a knife from the deceased's kitchen, and went with him to his bedroom. Sexual activity with one of the 'robbers', A1, continued to the point of ejaculation in the mouth of the deceased. According to A2, the three of them had sex together on the bed, prior to the homicide. It appears therefore to be only when the sexual activity was well advanced that the homicide occurred. The homicide involved stabbing the deceased some 40 times with the knife, an excessively violent murder, and well beyond the control necessary to effect a robbery. An attempt was then made to rob the house, but the assailants were interrupted and forced to flee the scene.

Equally intriguing, two days before the homicide, a witness statement indicates that A2 forced another young man at knifepoint to accompany him to an abandoned place. There, he forced the other man to fellate him, and to masturbate himself to the point of ejaculation. He then said, "I'm going to tell you one thing and once only, from now on you're my affair ... I'll be round at eleven and you had better be in". Before the appointed time, friends of the victim of this assault found A2 and in a bout of rough justice, threw him down a flight of stairs; A2 then left the victim alone. Nonetheless, this history makes the subsequent homicide considerably more interesting as a sexual crime. Certainly, categorising the events as a 'robbery' does not do justice to the complexity of the situation.

\section{Murder by Rent Boys?}

Male prostitution is sometimes associated with gay sexual homicide in the academic literature and by the police in the cases examined. Tomsen relates some of the sexual-advance related murders in his study to the activities of rent boys:

Evidence suggests that a regular number of fatal attacks were, or appear to have been, carried out by a subgroup of men who are heterosexually identified but whose culturally shaped relationships to dominant notions of masculinity

\footnotetext{
${ }^{18}$ In one case, involving a man killed with his lower garments around his ankles, it was ambiguous as to whether the death occurred in a sexual context or whether an intruder to his home surprised him in the act of defecation.
} 
are continually destabilised. Male prostitutes have featured as suspected or confirmed perpetrators in the deaths analysed in this research (including three killers in 38 tried matters). In other studies, they have formed a larger proportion of the perpetrator group. (Tomsen 2002: 87)

This approach is difficult to apply to the current study. Tomsen appears to view the sex workers in his study as a relatively clearly defined class. They constitute a separate group in his categorisation of employment, for example (Tomsen 2002: 21). The men who appear to have been paid for sex in the current study do not classify so readily. Between 20 and 26 perpetrators in this study appear to have been paid for sexual activity at some point in their past. Often, they do not appear to view this sexual activity as a profession however, and it usually does not appear to be their sole or even prime source of income. It is sometimes not even particularly clearly articulated that the relationship in question is one of prostitution. It is much more difficult to associate prostitution with the events surrounding the deaths. In only about three of the cases do the facts turn fundamentally on the prostitution itself, such as over a dispute over payment. Although in a larger number of cases it is certainly possible that the assailant was admitted to the home of the deceased on the expectation that payment would be made for a sexual encounter, there is usually no concrete evidence of this in the files.

Further, it is not at all obvious that the men paid for sex in the current study identify as heterosexual. In all but ten of the cases alleged to be prostitutes by the police or where there is evidence of payment for sex in the materials, there is also evidence that the men in question were sexually active with men without payment as well. For the remainder, there is little evidence of their sexual preferences, although five appear to be in or to have had significant relationships with women at or prior to the deaths. The conception of the men paid for sex as heterosexuals whose culturally shaped conceptions of their masculinity are continually destabilised is thus difficult to maintain in this study; or at least, it is difficult to see what their status as people paid for sex adds to the broader questions concerning their homosexual orientation.

In the current study, the prostitution scenario raises the same difficulties as the robbery one: it is a factual situation that may locate some of the crimes, but its explicative power is limited. The same sort of violent response occurs in these cases as is typical in the other sexual homicides. While the prostitution scenario may sometimes explain why the assailant is present, it has limited explicative value in explaining how the deaths occurred.

\section{The Question of Power}

The academic literature associates sexual crime and questions of power (eg. Hearn, 1998, ch 8; Meloy 2000, 14; Scully, 1990). The question of power is similarly impossible to avoid in the context of gay sexual murder, but the literature on heterosexual murder cannot be applied in an uncritical way. To begin by stating the obvious, that literature places gender difference at the centre of the analysis: it is about men being violent to women. In gay sexual homicide, the gender difference is absent. The specifics of patriarchal supremacy that underlie our understanding of violence by men on women do not readily apply. The literature articulates heterosexual violence in terms of punishment of women who transgress their 
subservient roles or wives who refuse to behave as the property of their husbands. There is no comparable framework for gay sexual homicides, at least in the nondomestic context of the cases studied herein. The homicides in question remain a male preserve: there is virtually no incidence of gay sexual homicides where women kill women. As such, like so much of violent crime (see eg., Newburn and Stanko 1994) gay sexual homicide is a male phenomenon. While it may thus be articulated in terms of masculinity, it is a masculinity in which women do not appear to play an express defining role. It is instead about masculinity as a broader set of social practices.

The literature surrounding masculinity as this broader set of social practices (eg., Connell, 1995 and 2000) raises different analytical problems, however. In Masculinities, Connell presents four studies of the dynamics of masculinity. The assailants have some similarities with Connell's young, working class men who 'live fast and die young' (Connell, 1995, ch 4). Like Connell's exemplars, the killers in this study have generally been marginalised by capitalist economic structures, have minimal education, have criminal records and histories of institutional confinement, and rely on benefits: they are people on the social periphery.

Connell argues that their practice of masculinity is a collective, at least as much as an individual, practice: it manifests itself in group behaviour. (Connell, 1995, 106-9). This is consistent with the literature on homophobic hate crime: it is practised primarily in groups (Hamner 1992; Comstock 1991; Craig, 2002). In this sort of analysis the result is, to use Connell's phrase, 'protest masculinity':

... violence, school resistance, minor crime, heavy drug/alcohol use, occasional manual labour, motorbikes or cars, short heterosexual liaisons. There is something frenzied and showy about it. It is not simply adopting the conventional stereotype of masculinity...

$* * *$

[T]his is a collective practice and not something inside the person. Very similar patterns appear in the collective practice of working class, especially ethnic minority, street gangs in the United States. There seems to be no standard developmental path into it, apart from the level of tension created by poverty and an ambience of violence. Through interaction in this milieu, the growing boy puts together a tense, freaky façade making a claim to power where there are no real resources for power. (Connell, 1995, 110-1)

Certainly there is much here that resembles the life and culture of the killers. At the same time, there are differences. Typically, gay homicide is not a collective practice. As noted above, the typical case is instead one assailant, acting alone on a solitary victim. Unlike what one would expect from homophobic hate crime, an anti-gay animus is present only very rarely. Certainly, some of the assailants assert their heterosexuality, and certainly, many indicate their dislike of the sexual advances to which they say they were subjected, but only very rarely is this phrased as animosity to gay people generally. 
Instead, the violence in these cases is articulated by the accused as a private event. Where the violence in Connell's example and in the homophobia literature is to make a show, to make a public display of ones masculinity, the violence of the gay killers tends to be reactive and private. If friends are told about it at all, it is often more by way of confession than boasting.

\section{Power in Private}

As noted above, the literature on heterosexual sexual crime tends to use patriarchy as an analytic model. In such heterosexual crime, men are already socially and economically dominant, and their crime is to reinforce and perpetuate that dominance over women, who are in turn socially, economically and often physically vulnerable. Such crimes in a heterosexual context are about men who have relative power using violence to perpetuate that power (see, eg., Hearn, 1998, 72).

Analysing the lines of power in relationships between assailants and their victims in the context of gay homicide is much more complex. The elder man may have the advantage of a gravitas that age brings, and sometimes will have greater economic stability. He may also have the authority that comes with a more settled life-style, at least in general having a flat to which the younger man may be brought. At the same time, the younger man may be physically more powerful. In gay sexual culture, youth has an allure and therefore a power. Finally, for much of the period of this study, the age of consent for sex between men was 21. A significant number of the deceased in this study would have been liable to prosecution, had the younger man notified the police of any sexual dalliances. It would thus be wrong to make simplistic assumptions about the location of power in these relationships.

Nonetheless, unlike the image of the male killers in heterosexual sexual crime, the assailants in this study appear to be remarkably vulnerable. The following case concerns the death of a man in his late 40s, killed by a man in his early $20 \mathrm{~s}$.

According to the accused, while he had met the deceased at a gay bar and believed him to be gay, he had gone home with the elder man not for sex, but because he needed a place to sleep following a fight with his boyfriend. According the police notes of the interview with the assailant, the deceased forced himself onto him:

'[A] started sobbing and continued, "We [A and D] had a row. I suppose that's why I did it. He forced me to have sex". A said "He'd tried to force me to have sex". I asked "What do you mean by 'sex'. How did he want to do it? Did he want to bugger you?" A said "What's bugger?" I said "You know - if you stick your cock into the arse or he does it to you". A said "No, he just tried to force me to gobble him". I said "Did he try to interest you in sex by exciting you and arousing you by playing with you?" A said "He just pushed his cock in my mouth". I said "You mean fellate or to have oral sex with you?" A replied "Yes." I said "What happened?" A said "He forced me to the floor and then he knelt on top of my chest. His trousers were open and he kept pushing my head onto his penis". I asked "Did you suck it until he came?" A said "I don't remember. I was drunk at the time. There was a fight and a piece of wood from the settee fell off." I said "Are you Gay?" A said "Yes". I said "Did you meet the victim D in [the gay bar] then go home with him?" A said "I went there just to sleep for the night". A then started to sob 
again. I said 'Are you OK, A?" A said "I'm just disgusted with myself for what happened". I said "Why did you have a row with [your boyfriend]?" A just shrugged and said nothing.'

In this case the assailant was known to be gay by his friends, and had a boyfriend at the time of the events. In a number of cases, this one included, it is extremely tempting to ask if the assailants can have been so naïve, given the situation they have gotten themselves into, as to be surprised at the sexual advance. In this case, the assailant went home with a man from a gay bar at closing time; the possibility that the partner was expecting a sexual encounter must have crossed the assailant's mind. This was certainly the view of the police in this case: in their view, the younger man was a rent boy, and the dispute was probably about payment. This is a problematic reading, however. Apart from references to the deceased by the assailant as a 'punter', a term which may but does not necessarily suggest payment for sexual activity in gay slang, there is little to support the prostitution theory.

If questioning the naivety of assailants is a tempting line of enquiry, it is also a difficult one, for several reasons. First, there are cases where there is at least some independent evidence that some assailants are, perhaps, that naïve. Regarding heterosexual assailants in gay murders, there is sometimes evidence that they may well not know the person they are going home with is gay. Further, for gay assailants, the scepticism makes assumptions about community practices in the gay community regarding caring for gay men in social need by other gay men. Particularly in the earlier part of the period under study, when that community was relatively small, it seems to have had had different expectations regarding mutual responsibility. This raises a variety of questions, largely outside the scope of this paper. A number of arrangements appear in the documents outside the assailant-deceased relationships where apparently vulnerable gay men are taken in by others in the community, sometimes on very little acquaintance. Some, but by no means all, involved sexual relations. Particularly those involving sex raise a wide variety of questions of power relations, not necessarily articulated by the parties. The existence of non-sexual relationships of this type makes the professed expectations of the assailants less unconvincing than they might at first appear.

Even if a sexual encounter is expected, the accounts of the accused suggest ambiguities relating to power and perceived choice. In the following case, the assailant, a man in his late twenties, met a considerably older man in a gay bar in central London and returned to the older man's flat:

We got a taxi just outside St. Martins in the Field Church, took us back to his flat, made us a cup of coffee once we got in the flat and started to take my clothes off and that er went to bed. He just started touching me up playing with my private parts you know. This had been going on for about ten or fifteen minutes or so. All I wanted to do was sleep you know, but I just started to feel this sense of nausea, disgust in myself, so I got up and went to the toilet. As I passed the toilet, there's a kitchen and I seen there was a knife lying next to the sink. I just picked it up and went back into the bedroom and they guy was er going to stand up and I just lashed out with the knife. I stabbed him in the neck. 
The assailant in the above case acknowledged that he had expected a sexual encounter would occur. Indeed, he did not consider it odd that the person taking him home would assume the assailant's consent to sexual activity, or assume that no further consent was necessary:

Q What made you pick up the knife?

A I just wanted to stop him doing what he was doing, I just wanted to go to sleep.

Q Why didn't you just tell him you wanted to go to sleep?

A He kept you know, it was natural to keep doing what he was doing without asking or anything.

The assailant changing his mind, simply saying no, was apparently not perceived as an option.

The scenario where the individual, while gay, states he does not expect sex to occur, or alternatively does not consent or withdraws consent to the sexual activity when it is instigated, is not uncommon in the cases, and raises questions about legal responses. The sense in the police records and questioning of accused persons ${ }^{19}$ is that if the individual was gay, and certainly if currently or ever a rent boy, he must have known what to expect. This view is thus similar to that expressed by the above assailant. This maps with difficulty onto traditional legal concepts. It is consistent with the law and heterosexual experience of sexual practice that consent may be withdrawn at any time; the same must apply to gay sexual activity. ${ }^{20}$ More relevant for the present paper, however, is that the assailant in question does not appear to have expected an occasion to withdraw consent following the return to the home of the deceased. Sex was perceived by the accused instead as a matter of inevitability.

A variation on this theme occurs in a different case, where the assailant acknowledges that a certain amount of sexual activity was expected in the situation, but his refusal of further sexual activity was not accepted. He had masturbated the deceased, but was not prepared to consent to sodomy; his view was that his previous activity had been 'reasonable' to 'pay' for his night's accommodation. He portrayed the insistence of the deceased for further sexual congress as the triggering factor in the attack.

The apparent powerlessness of the assailant does not necessarily mean the empowerment of the deceased. As discussed above, the deceased are also frequently socially marginalised, almost as much as their assailants. Further, in cases where assailants do indicate a wish to leave, they often also say that the deceased begged or pleaded with them to stay - hardly an attitude of power on the part of the deceased.

Other cases seem to involve the assailant viewing the introduction of a sexual element as a matter of betrayal in the elder man-younger man relationship. In several

\footnotetext{
${ }^{19}$ A similar view has been expressed in some audiences, gay and straight, when I have presented this paper orally in the past.

${ }^{20}$ In recent times, the Code for Crown Prosecutors makes this non-discriminatory policy clear, and anecdotal indications are that prosecutors are attempting to come to terms with the complexities to which these situations give rise.
} 
cases, even when the parties have only just met, the assailant portrays the deceased as almost a father figure, as in the following account:

I was walking up towards [a club] to go through because I had to walk it off because I was drunk, I seen this guy and he said to me, alright mate, where are you going, and I told him I was going home and he said, I'll give you a lift and I said no I need to walk home. And he said, it's freezing, so he said, I'll give you a lift in my car it's only down there, so I said, alright then, and then I was telling him then about my father and my father died on that day [...] I was upset and that and he put his arm around me and I thought nothing of it then, I just thought that he was comforting me because I was upset. And then he said, come on let's go I'll take you home man. When we was walking down to his car he tried it on with me so I just fucking flipped, I'm sorry, I didn't mean to kill him.

All these articulations suggest that the power relations between the assailant and the deceased were complex. That complexity follows through into the experience of the killing by the assailant and its aftermath. Frequently, the accused purports to remember little or nothing of the actual killing. In other cases, he describes a feeling of being taken over, and of losing himself in the event:

I went into the bedroom and I just started beating him with this cable. I didn't want to stop. My temper was at its highest I've ever known. I just couldn't stop. I was just screaming things at him. Not just at him, at everybody. I then stopped and sat down in the chair \& started laughing. I don't know why I was laughing because nothing was funny. He was crying on the bed. (crying). I cut the wire I'd tied him down with, I dragged him into the bathroom by his hair. I think I punched him in the face. I tied his hands to the bath rail. I remember he messed himself with fright. That made me angry again. Not a blind rage anger - something completely different. I could see what I was doing. I couldn't stop. I went to the kitchen and came back with a carving knife. I wasn't intending to stab him then I remember sitting on the edge of the bath \& I remember saying go him "If I let you go you won't tell anybody" He was looking at me in the eyes. Shook his head saying No. I went to untie him. I went to untie him \& he started to struggle to get away. I grabbed his hands and tied him back to the bath rail. I remember my anger was taking me to places I'd never been I felt exhilaration because of the power I had. I remember I think screaming at him and saying "you're a liar" if I let you go he would go \& tell. He was screaming thro' the gag, shaking his head saying no. I stabbed him in the stomach (crying). And then in the chest. I don't know how many times. (crying) I can remember the noise.

This is very different to the 'socially defined, even managed' violence in which Connell's groups of working class men engage (Connell, 1995, 107). It resembles much more closely the accounts described by Hearn of men's violence against women (Hearn, 1998, 100). Hearn views the accounts of the men he interviewed in the context of justifications and excuses, ways in which men fail to engage with their violence and normalise the continuation of their patriarchal power (Hearn, 1998, ch. $7,8)$. The accounts in the sample of gay homicides are much more ambiguous, as the above quotation demonstrates. Certainly, there is a sense in which the assailant 
describes an experience of power, but the euphoric experience of the power is undercut by the assailant crying through this passage of his account. He may have perceived the killing as triumphal, but also as tragic. The assailant is both powerful and, by losing himself, becomes powerless. If it is the apotheosis of his masculinity, it is also its undermining.

This is, perhaps, consistent with his broader socio-sexual context. Slightly later in the account, he says:

A. I looked at him and I remember I got scared. I ran into the front room and sat down for about $1 / 2$ an hour, maybe an hour I don't know, thinking of the consequences, what I was going to do \& why I had done it, why hadn't they listened.

'Q. Who's they, A.

'A. The authorities, the social workers, everybody.

This quotation associates the rage and violence with a feeling of power in the face of the assailant's actual and perceived social marginalisation. According to the traditional markers of masculinity, including employment and social achievement, A is a failure. His own view would appear to be that the killing does little to alter that.

Certainly, the accounts of the assailants must be viewed with some caution. The first of these assailants, for example, had previous convictions for assault causing actual bodily harm; the second had been convicted of a variety of sexual assaults, as well as a range of other criminal activity. The third had a string of offences mainly relating to property, but had only been released from prison shortly before his fatal assault on the person providing his accommodation. And the fourth, while only in his early twenties, had accumulated a record of property and violence offences running to three pages. These are not naïve angels; they are persons accused of a serious crime, with experience of the criminal justice system and an interest in portraying themselves in the way they think will best assist their case. While the consistencies between the accounts are significant, the context of the accounts cannot be ignored. In the one case in the sample where the deceased survived long enough to make a statement to the police, the general pattern of events was broadly consistent between accused and deceased, but in the version of the deceased, the accused was not an unwilling participant in the sexual congress.

\section{Gay Homicide and the Psychological Literature on Sexual Murder}

The placement of the violence within the individual, rather than as a collective practice, may suggest that psychological explanations for the violence may have a particular role to play in understanding gay sexual homicide. The forensic psychiatric and psychological literature does address sexual murder (Meloy 2000; Beauregard and Proulx 2002; Porter et al 2003; Schlesinger, 2004). Some of this literature can be seen to be relevant to some gay homicides. One category would appear to involve 'organised sexual homicide', for example (Meloy 2000: 6-7). These are generally preplanned murders, perhaps committed by people with obsessive-compulsive disorders, who maintain a sense of order in and about the crime scene. Some of these factors 
intersect with a small number of cases in the current sample. In a small number of cases, considerable care was taken by the perpetrator to ensure that the killing does not dirty the premises for example through controlling the spattering of blood, and returning the premises to order following the death goes well beyond that necessary to avoid detection. Even here, however, there are differences. The cases of this type in the current sample do not generally involve completion of sexual activity. They are included because when the parties meet, the expectation of one or both is that sexual activity will occur, but at or prior to that time or alternatively during the foreplay, the murderer decides that this will not be a sexual liaison, but rather a murder. To that end, he takes charge of the situation, often by physically restraining the victim, and sometimes following some form of torture or similar violence, kills him. These deaths, if they have ever had a sexual component in the mind of the perpetrator, have ceased to do so when the death occurs. Consistent with the findings of Schlesinger (Schlesinger 2004: ch 8), this scenario is most directly relevant to cases in the current sample where perpetrators kill more than one person. It therefore does not refer most directly to the bulk of the cases in the sample.

Other scenarios in the literature are even more difficult to apply in the context of gay sexual murder. The literature operates on the expectation that while the killer is male, the victim is female. This is to a degree understandable, as it would seem that a majority of sexual killings are of women by men (Schlesinger 2004: 8). Nonetheless, this imports a set of gender-defined dynamics, often not expressly articulated, into the analysis. These dynamics are often very difficult to apply to gay sexual homicide. The role ascribed to sexual fantasy in the literature links sexual murder to other forms of sexual violence. The murder becomes the acting out of a male sexual fantasy. This imports a fiercely gendered component into the understanding of the murders, with the powerful male perpetrator dominating the passive woman or girl. Fantasy is not a prevalent feature in the perpetrators' or the psychiatrists' accounts of the gay sexual homicides in the current study. Further, the dynamics of the fantasy implied in the heterosexual context are difficult to map onto the gay deaths. It is the person who is relatively vulnerable socially and economically who is the killer in these cases, not the person killed.

Gendered factors occasionally appear as an express part of the psychological understanding of sexual homicide. Some theories associate sexual killing of women by men with Oedipal dynamics, with the murder victim displacing the assailant's mother. The matricidal explanation of sexual murder is also obviously difficult to apply in a homosexual context.

Other theories place sexual murder in the context of a history of misogyny, and the crimes themselves may be theorised as displaced matricides (Meloy 2000: 14). Some alteration of these criteria is clearly required in the case of a male victim. Presumably, the equivalent of misogyny would be homophobia. As we have seen, such motives are only rarely articulated in the current sample. Where that poses a significant problem to the sociological theories of gay homicide, psychological theories can better accommodate repressed or subconscious factors. Certainly, the exceptional violence that results from the possibility of a sexual encounter with another man does suggest that some form of homophobia must be a factor. Sadly, this approach does not appear to have been taken up by psychologists at this time. 
Revitch and Schlesinger's motivational model of sexual homicide provides some potential framework for understanding the deaths. They place sexual homicide in the context of homicide more generally, on a continuum from those instigated by external or sociogenic stimuli, to those precipitated by internal or psychogenic factors. These do not correspond directly to diagnostic categories; they are rather social and psychological models, based on empirical analysis. Their spectrum has five categories, three towards the former end of the scale, and two towards the latter. They categorise homicides as environmental, situational, impulsive, catathymic, or compulsive (Schlesinger 2004: 91). When applied to sexual homicide, these categories suffer from the gendered articulation discussed above: the assumption is that this is about men killing women. Nonetheless, the categories do provide some assistance. Serial gay sexual killers, for example, have some similarities with people committing compulsive homicides.

The bulk of the cases in the current study are not serial killings, however. They are single assailants killing single individuals. These seem to fit best into the impulsive and acute catathymic categories. Schlesinger provides the following characteristics of impulsive offenders who commit homicide:

- History of multiple anti-social acts

- Offences are poorly structured, committed without planning

- Frequent involvement in amateurish and semi-professional crime

- Lifestyle characterised by lack of direction, random actions and unpredictability.

- Offenders are passive, easily led, and overreact to environmental circumstances

- Personality is loosely integrated, with strong feelings of inadequacy

- Frequent history of developmental disabilities (eg, ADHD, learning and speech problems, minor physical handicaps).

- Chronic feelings of hostility and anger, and a non-specific need for revenge.

- May not have impulse control disorder per se (Schlesinger 2004: 102).

There is a considerable overlap here with the offenders in the current sample. Much of this speaks directly to the questions of alienation shown above to be prevalent in the current sample of offenders: they have histories of anti-social acts and crime, lives with little direction, and histories of violence suggesting hostility and anger.

Placement of gay sexual homicide in this broader context of impulsive homicide generally suggests some consistency with Tomsen's approach to the crime, but places it in a broader perspective. Tomsen sees deaths flowing from personal disputes in private spaces, the category most prevalent in the current study, as intimately bound up with an affront to male honour:

These are cases where an advance seems to occur and perpetrators react with a great level of violence reflecting irrational elements of shock and outrage. These attacks are best explained in terms of the affront that a homosexual advance can bring to the sense of male honour and bodily integrity held by perpetrators. Just as gang attacks on homosexual targets reflect evident concerns with questions of masculinity, these incidents suggest a further relation between matters of male identity and the killings (Tomsen 2002: 689).

Pink_paper4_public_harvard.dft.doc $\quad-22$ - 
An application of such an attack on masculinity has already been considered, regarding Tomsen's discussion of male prostitutes, above.

Certainly, the undercutting of masculine identity would go a considerable way to explaining the disintegration of personality and feelings of inadequacy in the assailants; but the placement of this factor into the context of impulsive killing more generally allows a broader range of factors to be considered. The complexities of articulating these crimes as crises of masculinity have already been discussed. It does however seem that the assailants are placed in a position where they lose control over the situation. Considering these events as compulsive homicides allows issues of masculinity to be relevant to the analysis, but allows other factors to be relevant as well.

\section{Conclusion}

The body of evidence does seem to be sufficiently consistent that gay sexual homicide can and should be considered as a coherent and discrete set of cases. They cannot be simply be slipped into the analysis of heterosexual sexual murder: both demographically, and in terms of the dynamics between the protagonists, they are different. This paper is significant as much for the gaps it demonstrates as for its positive assertions. The sociological and psychological models may be convincing for male assailants and female victims; they have much less explicative power for sexual homicide between men.

The problem can be articulated as challenging implied assumptions. The literature of the last fifteen years has challenged the assumption that crime is gender neutral, and the insistence by the literature cited in this paper that crime, violent crime, and sexually violent crime is perpetrated overwhelmingly by men has yielded important results. The challenge of this paper is the placement in that literature of masculinity in juxtaposition to femininity, both in the locus of study (male perpetrators and female victims) and in the articulation of masculinity itself (juxtaposition to women is a part of how masculinity is defined; it is not the whole picture).

Clearly, more research is required. This paper has argued that some of the existing literature provides potential avenues for this research. Certainly, on a sociological level, there are questions of power that are relevant. The empirical analysis above suggests that a restriction of the study to the construction of masculinity, at least as narrowly defined, is likely to be inadequate to reach a satisfactory understanding of these homicides. Issues of class and personal history, for example, also seem inescapable. It is only when we have engaged in this broader study that an understanding of these homicides may begin to emerge.

There are limits to the explicative power of the sociology of masculinity, however. Insofar as that literature identifies violence as a communal activity, it is very difficult to apply to the cases in this study. This suggests that the sociological approaches may not be sufficient. Insofar as the violence is sited in the individual, rather than in social relations, psychological explanations may be essential to a fuller understanding. Here, research is at best in its infancy, and the particular problem of sexual homicide between men has thus far met with a resounding silence. 


\section{$\underline{\text { References }}$}

Banks, K. (1997), 'The "Homosexual Panic" Defence in Canadian Criminal Law', [1997] Criminal Reports ( ${ }^{\text {th }}$ series) 371.

Beauregard, E, and Proulx, J. (2002), 'Profiles in the Offending Process of Nonserial Sexual Murderers', International Journal of Offender Therapy and Comparative Criminology 46/4: 386.

Comstock, G. (1991), Violence against Lesbians and Gay Men. New York: Columbia University Press.

Comstock, G. (1992), 'Dismantling The Homosexual Panic Defense', 2 Law and Sexuality 2: 81 .

Connell, R. (1995), Masculinities. Cambridge: Polity.

Connell, R. (2000), The Men and the Boys. Berkeley: University of California Press. Craig, K. (2002), 'Examioning Hate-Motivated Aggression: A Review of the Social Psychological Literature on Hate Crimes as a Distinct Form of Aggression', Aggression and Violent Behavior (2002) 7:86.

Dressler, J. (1995), "When "Heterosexual" men kill "Homosexual" men: Reflections on Provocation Law, Sexual Advances, and the "Reasonable Man" Standard', Journal of Criminal Law and Criminology 85: 726-763.

Editors of the Harvard Law Review. (1989), 'Recent Developments: Sexual Orientation and the Law', Harvard Law Review 102: 1508;

Gemert, F. (1994), 'Chicken kills hawk: Gay murders during the eighties in Amsterdam', Journal of Homosexuality, 26/4: 149.

Grubin, D. (1994), 'Sexual Murder', British Journal of Psychiatry 165: 624

Hamner, K. (1992), 'Gay-Bashing: A Social Identity Analysis of Violence against Lesbians and Gay Men', in Herek G, and Berrill K, (eds), Hate Crimes: Confronting Violence Against Lesbians and Gay Men, 179, Newbury Park: Sage.

Hearn, J. (1998), The Violences of Men. London: Sage.

Janoff, D. (2005), Pink Blood: Homophobic Violence in Canada. Toronto: University of Toronto Press.

Lunny, A. (2003), 'Provocation and 'Homosexual' Advance: Masculinized Subjects As Threat, Masculinized Subjects Under Threat', Social and Legal Studies 12/3: 311333;

McConville, M, Sanders, A, and Leng, R. (1991), The Case for the Prosecution: Police Suspects and the Construction of Criminality London: Routledge.

Meloy, R. (2000), 'The Nature and Dynamics of Sexual Homicide: An Integrative Review', Aggression and Violent Behavior, 5/1: 1.

Mison, R. (1992) 'Homophobia in Manslaughter: The Homosexual Advance as Insufficient Provocation', California Law Review 80: 133.

Mouzos, J, and Thompson, S. (2000), 'Gay-Hate Related Homicides: An Overview of Major Findings in New South Wales, Trends and Issues in Crime and Criminal Justice, paper \#155, (Canberra: Australian Institute of Criminology.

New South Wales, Attorney General's Department, Criminal Law Review Division. (1998), Homosexual Advance Defence: Final Report of the Working Party. Sydney: NSW AG.

Newburn, T. and Stanko, E. (1994), Just Boys Doing Business? Men, Masculinities and Crime. London: Routledge. 
Oliver, S. (1999), 'Provocation and Non-violent Homosexual Advances', Journal of Criminal Law 63/6: 586.

Porter, S, Woodworth, M, Earle, J, Drugge, J, and Boer, D. (2003), 'Characteristics of Sexual Homicides Committed by Psychopathic and Nonpsychopathic Offenders', Law and Human Behavior 27/5: 459.

Sanders, A. (1987), 'Constructing the Case for the Prosecution', Journal of Law and Society, 14: 229.

Sanders, A. (1997), 'From Suspect to Trial', in Maguire, Morgan and Reiner, eds., The Oxford Handbook of Criminology. $2^{\text {nd }}$ ed, Oxford: Oxford University Press.

Schlesinger, L. (2004), Sexual Murder: Catathymic and Compulsive Homicides. Boca Raton: CLC Press.

Scully, D. (1990), Understanding Sexual Violence: A Study of Convicted Rapists. Boston: Unwin Hyman.

Soothill, K,et al. (1999), Homicide in Britain: A Comparative Study of Rates in Scotland and England and Wales. Edinburgh: Scottish Executive Central Research Unit.

Tomsen, S. (2002), Hatred, Murder and Male Honour: Anti-Homosexual Homicides in New South Wales, 1980-2000, Research and Public Policy Series no 43, Canberra: Australian Institute of Criminology.

Pink_paper4_public_harvard.dft.doc - 25 - 